This is an Accepted Manuscript of an article published by Taylor \& Francis in Annals of Human Biology on 45:3, 220-228, DOI: 10.1080/03014460.2018.1459837

The final published article is available online at https://pubmed.ncbi.nlm.nih.gov/29606018/ or https://www.tandfonline.com/doi/abs/10.1080/03014460.2018.1459837

\title{
Relationships between psychosocial distress and diet during pregnancy and infant birthweight in a lower-middle income country: "Healthy mothers, healthy communities" study in Vanuatu
}

Alysa Pomer ${ }^{1}$, Giavana Buffa ${ }^{2}$, Fasiah Taleo ${ }^{3}$, J. Hunter Sizemore ${ }^{4}$, Apisai Tokon ${ }^{3}$, George Taleo $^{3}$, Len Tarivonda ${ }^{3}$, Chim W. Chan ${ }^{5}$, Akira Kaneko $^{5}$, Kelsey N. Dancause ${ }^{6}$

1. Department of Chronic Disease Epidemiology, Yale School of Public Health, New Haven, CT, USA

2. Ross University School of Medicine, Portsmouth, Dominica

3. Ministry of Health, Port Vila, Republic of Vanuatu

4. Peace Corps Vanuatu, Port Vila, Republic of Vanuatu (former)

5. Island Malaria Group, Department of Microbiology, Tumor and Cell Biology (MTC),

Karolinska Institutet, Stockholm, Sweden

6. Départment des sciences de l'activité physique, Université du Québec à Montréal, Montréal QC

\section{Address of corresponding author}

Kelsey Dancause, $\mathrm{PhD}$

Université du Québec à Montréal (UQAM)

141, avenue du Président-Kennedy

Montréal, QC Canada H2X 1Y4

Phone (514) 987-3000 ext. 5263, e-mail kelseydancause@ gmail.com 


\section{Relationships between psychosocial distress and diet during pregnancy and infant birth weight in a lower-middle income country: "Healthy mothers, healthy communities" study in Vanuatu}

Background: Maternal stress during pregnancy is associated with birth outcomes, including birthweight. Exposure to natural disasters during pregnancy provides a model to study these relationships. However, few studies assess both stress and diet, which might have interactive effects. Furthermore, most are conducted in high-income countries. Patterns might differ in lowand middle-income countries (LMICs).

Aim: To study relationships between stress and diet during pregnancy, and infant birthweight, following a natural disaster in a lower-middle income country.

Subjects and methods: In 2015, the island nation of Vanuatu suffered a Category 5 cyclone. Three months later, we assessed hardship due to the cyclone, distress, and dietary diversity among 900 women, including 187 pregnant women. Of these, 70 had birth records available. We used multivariate linear regression to analyze relationships between cyclone exposure and infant birthweight among this subsample.

Results: Neither hardship nor dietary diversity predicted birthweight. Distress was a robust predictor, explaining $8.5 \%$ of variance $(\mathrm{p}=0.012)$. There were no interactive relationships between distress and other exposure variables.

Conclusions: Maternal distress following a natural disaster has important implications for maternal and child health. In LMICs, low birthweight remains a pressing public health concern. Distress during pregnancy might represent one underlying risk factor.

Keywords: DOHaD, Vanuatu, maternal and child health, mental health, low birthweight 


\section{Introduction}

Prenatal stress is increasingly accepted as a risk factor for adverse birth outcomes (Hobel et al. 2008). The underlying mechanisms are varied, including effects of maternal stress hormones, which can cross the placental barrier and affect fetal development (Lazinski et al. 2008); maternal physiological changes in response to stress, such as changes in blood circulation that could also alter blood flow to the placenta (Hobel et al. 2008; Maric et al. 2010); and epigenetic changes in developing placental and fetal tissues (Monk et al. 2012). Prenatal stress is a risk factor for smaller birth length (Lederman et al. 2004; Dancause et al. 2011b; Frith et al. 2013), weight (Lederman et al. 2004; Maric et al. 2010; Frith et al. 2013), and gestational age (Lederman et al. 2004; Dancause et al. 2011b; Frith et al. 2013); low birthweight (LBW; birthweight less than 2500g) (Xiong et al. 2010; O'Donnell and Behie 2013); and preterm birth (Glynn, Wadhwa, Dunkel Schetter, et al. 2001; Xiong et al. 2010; Torche and Kleinhaus 2012; O'Donnell and Behie 2013). Effects often vary by timing of exposure (Glynn, Wadhwa, DunkelSchetter, et al. 2001) and newborn sex (Ellman et al. 2008). Birthweight is of particular interest because it is associated with a number of immediate and long-term health outcomes. LBW is a major predictor of infant mortality, and remains a persistent public health concern, especially in low- and middle-income countries (LMICs) (Abu-Saad and Fraser 2010; WHO 2014). Additionally, LBW is associated with later development of chronic disease, including diabetes and cardiovascular conditions (Barker 2004), as well as with negative mental health outcomes, such as depression (Loret de Mola et al. 2014). Relationships between birthweight and developmental outcomes are observed not only for infants with LBW but across the continuum of birthweight measures (Walhovd et al. 2012).

One cannot randomly assign pregnant women to stress or non-stress groups, so prenatal stress research relies largely on the assessment of stressful life events (such as divorce) or psychosocial traits that might be correlated with stress, such as anxiety. This imparts limitations, as anxiety and life events are not randomly distributed, but might be associated with other maternal sociodemographic, genetic, or other characteristics that affect child development. Furthermore, the effects of prenatal stress might vary depending on the timing of exposure during fetal development. However, many life events have long onset that make it difficult to establish timing with precision (King et al. 2012; King and Laplante 2015). 
Natural disasters provide excellent models of prenatal stress because the stressor affects many people at once and is largely independent of maternal characteristics, and because the timing of exposure can be identified with precision. Results from the Stress in Pregnancy International Research Alliance (SPIRAL), a group studying stress among women who were pregnant during natural disasters, show effects of the timing and severity of exposure to natural disasters during pregnancy on outcomes at birth and throughout childhood (King et al. 2012; King and Laplante 2015). For example, studies of children who were in utero during a severe ice storm in Quebec (Project Ice Storm) showed that mid-gestation exposure to the ice storm predicted lower birth weight (Dancause et al. 2011b), and greater stress in early gestation predicted smaller head circumference (Dancause et al. 2011b). Similar studies in Australia (the Queensland Flood Study) showed that maternal dietary change in response to stress mediated the relationship between distress due to flooding and infant head circumference at birth (Dancause et al. 2017), highlighting the importance of assessing both diet and distress.

Despite advances in our understandings of prenatal stress and birth outcomes, our most comprehensive studies of prenatal stress are in industrialized nations (Ramchandani et al. 2010). It is unclear how the effects of stress during pregnancy might differ in low- and middle-income countries (LMICs). Given the persistence of adverse birth outcomes in many LMICs, even modest effects of the prenatal environment might hold important public health implications. Furthermore, considering the vulnerability of populations in LMICs to natural disasters (Lee et al. 2014), characterizing the impact of such events on the health of pregnant women and their infants is necessary.

\section{The "Healthy Mothers, Healthy Communities" Study in Vanuatu}

Since 2007, we have studied population health in Vanuatu, a lower-middle income country in the South Pacific (Dancause et al. 2011a; Dancause et al. 2012b; Dancause et al. 2013b; Olszowy et a. 2015; Olszowy et al. 2017; Sun et al. 2017; Weitz et al. 2017). In 2015, we created the "Healthy Mothers, Healthy Communities" Study to assess the role of maternal health during pregnancy on infant and child health outcomes. We planned to assess data on major life events, perceived stress, anxiety, depression, and health behaviors among pregnant women, and to follow their infants' development from birth to age 2 . 
However, the study was abruptly modified when, in March 2015, the nation was hit by Cyclone Pam, a Category 5 cyclone that left many villages in ruins. Approximately $80 \%$ of Vanuatu's rural population was affected by crop loss and damage as a result of wind and salt water inundation (Government of Vanuatu 2015). This also affected urban populations, which rely on fresh foods brought from the rural regions and sold in the marketplaces of the urban centers. Prices of staple foods increased by as much as $300 \%$ after the cyclone (Government of Vanuatu 2015). We thus created a study of stress and diet among women exposed to the cyclone during pregnancy, and infant development. We assessed objective hardship, distress, and diets following the cyclone, and their relationships with infant development, based our past experience studying prenatal stress due to natural disasters.

\section{Objectives \& Hypotheses}

Our objective in the current study was to assess relationships between exposure to Cyclone Pam during pregnancy and infant birthweight. We hypothesized that greater objective hardship, greater distress, and lower dietary diversity would be independent predictors of lower birthweight, and that distress and dietary diversity would have interactive effects.

\section{Methods}

This study was reviewed and approved by the Comité institutionnel d'éthique de la recherche avec des êtres humaines (Institutional Committee on Ethics for Research Involving Humans) at the Université du Québec à Montréal, and by the Vanuatu Ministry of Health.

\section{Sample}

In June-July 2015, we collected data on damage and hardship due to the cyclone, psychosocial distress, and diets among women of reproductive age in Vanuatu. Sampling was conducted on four islands. On Efate, the home of the urban capital Port Vila, we conducted convenience sampling at local clinics, the women's center, and the local open-air market, where women sell fruits and vegetables from Monday-Saturday. On three other islands (Aneityum, Tanna, and Erromango), we conducted similar convenience sampling at local clinics. We also worked in collaboration with a team that conducted malariometric surveys among 3009 people in 12 rural communities (Chan et al. 2017). We sampled among reproductive-age women who attended the malariometric screenings. The total sample included more than 900 women, 
including 187 women who were pregnant during the cyclone or who became pregnant within the following three months when stress hormones could still be elevated.

Following delivery, we collected birth records from local hospitals and clinics to provide data on date of birth and birthweight of the women's infants, and parity. We were able to identify birth records for 76 of the 187 pregnant women (40.6\%). In Vanuatu, birth records consist of a single line of hand-written notes kept in a large book in the hospital or clinic. Women are usually identified by name, age, parity, and village of residence. Because of imprecisions in data entry (such as recording only the first name), matching women to birth records with confidence is challenging. However, this is not likely to introduce systematic bias into the analyses. In particular, there were no differences in sociodemographic variables, or in hardship, distress, or diet variables, among women who were successfully matched to birth records and those who were not except parity, which was lower among women with birth records (1.9, $\mathrm{SD}=1.6)$ compared to women with no birth records $(2.5, \mathrm{SD}=1.9 ; \mathrm{p}=0.011)$.

\section{Instruments}

We created a self-administered questionnaire to assess maternal sociodemographic data (age, education, number and ages of children), pregnancy status, stress, and diet following the cyclone. Past studies of prenatal stress, including our own, distinguish between objective hardship (i.e. what happened) and subjective distress (i.e. how the participant responded). We followed similar methods in the current study. Surveys were in Bislama, a Melanesian pidgin language used across Vanuatu. Maternal age and number of children were compared to data on parity recorded in medical records for verification.

\section{Cyclone Exposure Variables}

Objective hardship: We assessed damage to women's village, home, and garden. Responses for each category were on a 4-point scale from "Good, untouched by cyclone" (1) to "Severe damage, must rebuild" (4). We summed responses across the three categories. Scores in the current sample ranged from 5-12. Questionnaires also included loss of livestock and property and days without adequate food and water. These were not included in objective hardship scores, but their relationships with birthweight were analyzed separately. 
Distress: Distress was evaluated using a Bislama adaptation of Impact of Events Scale Revised (IES-R) (Weiss and Marmar 1997). This 22-item scale describes symptoms from three categories relevant to post-traumatic stress disorder (PTSD): intrusive thoughts, hyperarousal, and avoidance. Participants report the extent to which each behavior describes how they felt over the preceding seven days. Responses are on a 5-point Likert scale from "Not at all" (0) to "Extremely" (4). Items were written to reflect symptoms relative to the cyclone. We translated questions and responses into Bislama and reviewed them with native speakers. Some vocabulary was not directly translatable, leading to repetition in some items. We retained three questions from each category of PTSD symptoms (Appendix 1). The mean of response values for all 9 items was used for analyses. Scores in the current sample ranged from 0-4.

Diet/Dietary Diversity: We collected 24-hour recall and classified foods into nine groups based on micronutrients using the Women's Dietary Diversity Score (Food and Agriculture Organization 2010). Dietary Diversity was calculated as the number of groups represented in the 24-hour recall. Values in the current sample ranged from 1 to 7.

Timing of Exposure: Timing of exposure to the cyclone during gestation was defined as 280 (the length of a normal pregnancy) minus the difference between the beginning of the cyclone (March 13, 2015) and the date of birth. Thus, larger values represent exposure later in pregnancy. Thirteen women were exposed to the cyclone in the $3^{\text {rd }}$ trimester (187-280 days gestation), 28 in the $2^{\text {nd }}$ trimester (94-186 days gestation), and 16 in $1^{\text {st }}$ trimester (0-93 days gestation). Three became pregnant in the six weeks following the cyclone.

\section{Outcomes}

From hospital records, we recorded date of birth, birthweight (g), gestational age (weeks), and Apgar scores at 1, 5, and 10 minutes, as well as notes about the health of the mother and baby. We computed birthweight Z-scores based on World Health Organization standards (World Health Organization 2017).

\section{Analyses}

We examined descriptive statistics and correlations among variables. We conducted linear regression analyses to test relationships between maternal hardship and distress due to the cyclone and dietary diversity, and infant birthweight. We first tested hardship, distress, and 
dietary diversity independently in three separate models. In Block 1, we controlled for maternal age, parity, years of education, and infant sex. In Block 2, we entered days of exposure. In Block 3, we entered hardship, distress, or dietary diversity.

Based on results of these analyses, we conducted a second set of regression analyses to test interactive relationships between distress and dietary diversity, and distress and objective hardship; and to test a final model including all cyclone exposure variables. Analyses were conducted in SPSS version 22.0 (Armonk, NY: IBM Corp.).

\section{Results}

\section{Descriptive statistics}

Among the 76 women with birth records, 6 were excluded from analyses. Birthweight was not recorded for infants of two women. One woman with twins, and one woman whose infant was stillborn, were excluded. Finally, two women had incomplete questionnaire data, leaving 70 women for analyses. Fourteen women had already given birth at the time of the survey, whereas 56 gave birth later. Thus, data were collected prospectively for $80 \%$ of the sample. The number of children at the time of the questionnaire ranged from 0 (for primiparous women with no adopted children) to 6 . These figures were consistent with the data on parity recorded in medical records for all except one woman, who had one adopted child and whose number of children was thus greater than parity. Descriptive statistics for the 70 women included in analyses are presented in Table 1.

Mean birthweight and birthweight Z-scores did not differ among boys (3352 g, SD=394; $-0.02,0.82)$ and girls $(3165 \mathrm{~g}, \mathrm{SD}=387 ;-0.18,0.91)(\mathrm{p}=0.136 ; \mathrm{p}=0.690)$ or based on trimester of exposure $\left(3^{\text {rd }} \mathrm{T}=3208 \mathrm{~g}, \mathrm{SD}=290 ; 2^{\text {nd }} \mathrm{T}=3292 \mathrm{~g}, \mathrm{SD}=391 ; 1^{\text {st }} \mathrm{T}=3358 \mathrm{~g}, \mathrm{SD}=355\right.$;

Preconception=2695 g, SD=746) $(\mathrm{p}=0.053)$.

Correlation among variables are shown in Appendix 2.

\section{Predictors of birthweight}

Multivariate linear regression analyses controlling for maternal age, parity, education, infant sex, and exposure timing indicated that distress was the strongest predictor of birthweight. At entry into the model, objective hardship explained $0.7 \%$ of variance $(\mathrm{p}=0.489)$. Dietary diversity did not explain any variance in birthweights $\left(\mathrm{R}^{2}=0.000, \mathrm{p}=0.937\right)$. Days without 
adequate food $\left(\mathrm{R}^{2}=0.025, \mathrm{p}=0.194\right)$ and water $\left(\mathrm{R}^{2}=0.042, \mathrm{p}=0.091\right)$ were also not significant predictors. Distress was a robust predictor of birthweight, explaining $8.5 \%$ of variance $(\mathrm{p}=0.012)$. Variance inflation factors were low (less than 1.2 for all variables), suggesting little collinearity. Table 2 shows standardized coefficients and p-values for final models testing objective hardship, dietary diversity, and distress.

Based on these results, we tested interactive relationships and models controlling for all variables. We observed no interactive relationships between distress and dietary diversity $\left(\mathrm{R}^{2}=\right.$ 0.001, $\mathrm{p}=0.822)$, nor between distress and objective hardship $\left(\mathrm{R}^{2}=0.003, \mathrm{p}=0.612\right)$. Finally, we tested whether the relationships between distress and birthweights persisted when controlling first for objective hardship and dietary diversity. Distress remained a significant predictor, explaining $8.8 \%$ of variance $(\mathrm{p}=0.011)$. Variance inflation factors were again low $(1.3$ or less for all variables), indicating little collinearity. Table 3 shows standardized coefficients and p-values for final models testing objective hardship, dietary diversity, and distress together.

We re-tested all models replacing birthweight with birthweight Z-scores, and replacing parity with number of children at the time of the questionnaire. Results were unchanged (data not shown).

\section{Discussion}

The goal of the current study was to assess relationships between prenatal stress due to a natural disaster, and dietary diversity following the event, on infant birthweight in a lowermiddle income country (LMIC). As observed in other studies, greater distress due to the disaster predicted lower birthweight. However, surprisingly, objective hardship and dietary diversity did not predict birthweight. Effects of distress were robust and persisted even controlling for other cyclone exposure variables, highlighting the importance of psychosocial health following disasters among pregnant women.

Results from studies of the Stress in Pregnancy International Research Alliance team often show strong results of objective hardship on child outcomes, including measures of physical growth. Objective hardship due to a severe ice storm in Canada predicted body mass index and obesity risk in childhood (Dancause et al. 2012a; Liu et al. 2016), cognitive and language development in childhood (Laplante et al. 2004; Laplante et al. 2008), and insulin secretion in adolescence (Dancause et al. 2013a). In contrast, hardship as a result of the cyclone 
was an unexpectedly poor predictor of birthweight in the current study. We expected that women experiencing greater objective hardship would also experience greater distress and lower dietary diversity as a result of food insecurity due to the hardships created by the cylcone. The expectation was that these factors would culminate in lower birthweight. However, areas with the most damage from the cyclone were often where aid was focused first (WFP 2015). This may have mitigated the effects of severe loss and property damage. Objective hardship was not significantly correlated with dietary diversity three months after the cyclone $(r=-0.166, p=0.169)$. Furthermore, although objective hardship was correlated with distress three months after the cyclone $(r=0.284, p=0.019)$, the strength of this relationship would be expected to diminish with time. The effects of objective hardship on outcomes at birth, several months later for most women, were likely alleviated by major recovery of damages in the months following the cyclone. In contrast, women in the SPIRAL studies in industrialized countries had other persistent burdens such as time off of work and dealing with insurance companies that were incoprorated into the objective hardship calculation (King et al. 2015) but that are not pertinent in Vanuatu or in many similar LMICs.

Similarly, maternal dietary diversity three months after the cyclone did not explain any variance in birthweight. Previous studies investigating dietary supplementation during pregnancy indicated that simple caloric supplementation had little impact on infant birthweight (Abu-Saad and Fraser 2010), but targeted macro nutrient or multimicronutrient supplementation has been shown to decrease the risk of low birthweight in low-income and developing nation populations (Shah et al. 2009; Imdad and Bhutta 2012; Haider and Bhutta 2015). Because dietary diversity evaluates micronutrient adequacy (Food and Agriculture Organization 2010), we might expect a positive association between maternal dietary diversity and birthweight. However, mean dietary diversity in the sample was low (mean=3.1 of a possible 9). It is likely that few participants were taking in adequate micronutrients, even among those with a high dietary diversity score within the sample. Furthermore, after the cyclone, the food shortage was exacerbated by a prolonged ElNino induced drought (Eriksson et al. 2017), which might have resulted in low dietary diversity throughout pregnancy and among the community as a whole. Limited variability in dietary diversity scores might underlie the lack of relationship with birthweight. Furthermore, results might reflect an underlying adaptation to low dietary diversity. If women had low dietary 
diversity (and thus likely inadequate micronutrient intake) before the cyclone, a slight further decrease may not cause disruption to fetal growth.

We expected to observe interactive relationships between distress and dietary diversity. Food insecurity is a major source of daily stress in developing populations, especially for women (Weaver and Hadley 2009). Similarly, micronutrient deficiency has been associated with mood disorders such as depression, anxiety, and stress (Kaplan et al. 2007), and affects females more strongly than males (Benton et al. 1995). This indicates a deeper interplay between dietary diversity and distress that may lead to intrauterine growth restriction and lower birthweight. While dietary diversity was indeed correlated with distress $(\mathrm{r}=-0.374, \mathrm{p}=0.002)$, it did not exacerbate the effects of distress on birthweight.

The factor that best predicted variance in birthweight after the cyclone was distress, showing surprisingly robust relationships even when controlling for hardship and dietary diversity. The distress measure captures symptoms of hyperarousal, intrusive thoughts, and avoidance following a stressful event, which can persist long after the event. Furthermore, given limited mental health service provisions in Vanuatu (Government of Vanuatu 2009), as in many LMICs, mental health interventions were not available to the majority of the affected population following the disaster. The persistence of distress symptoms - potentially thoughout a large part of the pregnancy for many women - could underlie the relationships observed between distress and birthweight.

Other studies following natural or man-made disasters have shown similar relationships between prenatal stress and birthweight. For example, retrospective cross-sectional studies following the 1999 bombing of Belgrade showed that infants of mothers exposed to the bombings during pregnancy had lower birthweight than those born to women who were pregnant in 1996 and 2003, when no stressful events affected the city (Maric et al. 2010). Similarly, studies following Hurricane Katrina in the US showed that high hurricane exposure (a measure combining both objective hardship and subjective distress measures) predicted low birthweight (Xiong et al. 2008). It is not necessarily clear from these studies which element of the stress exposure and response - objective hardship or distress - has the strongest relationships with birthweight. Our current results highlight the critical role of maternal distress, even controlling for objective hardship. 
Few other studies in LMICs have analyzed relationships between maternal distress and infant birthweights following natural or man-made disasters. One study in Thailand (Sanguanklin et al. 2014) analyzed depressive symptoms among 175 women who were at 26-38 weeks of pregnancy during a flood. Controlling for confounders, depressive symptoms did not predict birthweight, nor did displacement or social support. The authors note that depressive symptoms did not differ between displaced and nondisplaced women, and suggest that even women who were not displaced might worry over their friends and family, and experience adverse psychosocial health outcomes as a result. Studies of 25 women in the Democratic Republic of Condo (Mulligan et al. 2012) used ethnographic interviews as well as a Post-Traumatic Stress Disorder questionnaire to analyze the effects of wartime stress on birth outcomes and methylation profiles in maternal and cord blood. Results showed associations between maternal deprivation (e.g. clothing, housing, and other material goods), "mundane stressors" (e.g. prenatal care, home life, trauma), and war stress (with 6 questions on rape and 3 on kidnapping, refugee status, and death of a family member) with offspring birthweight. This study provides very important insights from a highly-stressful, non-Western setting. However, it is difficult to distinguish the effects of distress specifically from those of depression, trauma, social support, resources, as well as food security and chronic illnesses. The relative lack of studies on maternal stress and infant development following disasters in LMICs likely reflects the difficulty of reaching affected communities in time, as well as limited research and healthcare infrastructure that complicates data collection and follow-up. Furthermore, linguistic and cultural differences might complicate the adaptation of common psychosocial health assessment tools for use in LMICs.

Others in LMICs have analyzed anxiety, depression, life events, and perceived stress in daily life, and relationships with birthweight. For example, low birthweight was associated with high state anxiety among women in Iran (Nasiri Amiri et al. 2010) and with depressive symptoms and anxiety among women in Bangladesh (Nasreen et al. 2010). Similarly, two studies used the General Health Questionnaire to assess minor psychiatric disorders among pregnant women, one in Brazil (Rondó et al. 2003) and one in Sri Lanka (Ruwanpathirana and Fernando, 2014). Results showed that higher scores predicted low birthweight and small for gestational age, respectively. Two studies of depression, one in Ethiopia (Wado et al. 2014) and one in South Africa (Brittain et al. 2015), showed that depressive symptoms predicted low birthweight and 
birthweight Z-scores, respectively. Studies in Nicaragua (Valladares et al. 2009) showed that low social resources and high perceived stress predicted increased cortisol, and that increased cortisol then predicted low birthweight. Similarly, studies of perceived stress among Romanian women in a smoking cessation program showed that high stress predicted lower birthweight (Meghea et al. 2014). Studies in China showed that experiencing stressful life events during the $1^{\text {st }}$ trimester predicted lower birthweight, although there were no significant relationships following exposure in the $2^{\text {nd }}$ or $3^{\text {rd }}$ trimester (Zhu et al. 2010). Finally, studies in South Africa showed that experiencing stressful life events in the year before delivery predicted lower birthweight in one cohort (Rothberg et al. 1991).

These studies provide important insights on relationships between more long-term maternal psychosocial health characteristics and infant size at birth. Results from our study and others following independent stressors help to distinguish the effects of distress from those of other factors, supporting the independent effects of psychosocial health on birth outcomes. Furthermore, they highlight that effects are not limited to individuals with anxiety, depression, or other persistent psychosocial disorders, but that stressful events affecting the community as a whole might have widespread effects. The Government of Vanuatu has highlighted the importance of psychological distress following the cyclone and similar stressful events (Government of Vanuatu 2015), with a priority to expand mental health provisions. Similar efforts on the part of other countries might have measurable benefits not only for adult health and wellbeing, but for the health of infants at birth.

\section{Strengths and Limitations}

Our study is limited by the sample size, the data collection timeline, and the adaptation of instruments used. As noted above, linking study participants to birth records is difficult in Vanuatu. Continued follow-up is planned to assess later infant development measures among all pregnant women in the sample. The collection of data at only one time point also provides a limited window into maternal characteristics that might have affected birthweight throughout pregnancy. For example, the prolonged drought that followed Cyclone Pam likely caused prolonged low dietary diversity that was not captured in our surveys (Eriksson et al. 2017). However, the inclusion of women from all trimesters allows us to consider the role of the timing of exposure on outcomes. Furthermore, in order to limit the length of the questionnaire, we 
restricted our data collection to key sociodemographic, hardship, diet, and distress variables. More detailed assessment of maternal and household characteristics, especially potential moderators of distress such as coping styles and social support, would provide a more nuanced perspective and represent an important area for future research. Finally, we were unable to reliably translate all items on the original Impact of Events Scale - Revised, which limits our ability to define Post-Traumatic Stress Disorder among the sample and to directly compare our results with others. Nevertheless, the adaptation of this validated and widely-used measure is an important strength of the study. Our study is also strengthened by the prospective longitudinal design. Retrospective studies of stress suffer from the fact that women's responses might be biased by their perceptions of their infants' health. Eighty percent of participants completed the questionnaires before giving birth. Thus, their responses to our questionnaire items were not biased by the outcomes of their pregnancies. Finally, the inclusion of women from several islands and villages provides for broader generalizability of results.

\section{Conclusions}

Populations in LMICs are increasingly vulnerable to natural disasters, which might have important implications for dietary patterns and psychosocial health and, for pregnant women, the outcomes of their babies at birth. Efforts to increase psychosocial health resources and infrastructure in LMICs might have the dual benefit of improving adult health and wellbeing, as well as infant health outcomes. Where small size at birth remains a persistent problem, this could represent a particularly important public health initiative. 


\section{Declaration of Interest Statement}

The authors report no conflicts of interest. The authors alone are responsible for the content and writing of the paper.

\section{Funding}

This work was supported by funds from the Wenner-Gren Foundation for Anthropological Research, the Natural Hazards Center, and the Faculté des sciences of the Université du Québec à Montréal. KND was supported by a salary award from the Fonds de recherche du Québec Santé while working on this project.

\section{Acknowledgements}

This study grew out of our collaborations with the Health Transition in Vanuatu research team, led by Ralph Garruto and J. Koji Lum (Binghamton University), and the Stress in Pregnancy International Research Alliance, led by Suzanne King (McGill University). We are deeply appreciative of local malaria team, who continue to allow us to work alongside them in the outer islands, including Harry Iata, James Yaviong, Morris Kalkoa, and Sam Yamar. We are grateful to the women in the Vila Central Market who helped distribute questionnaires; Christiane Damassing for her assistance with recruitment; Christine Jackson, for her assistance with accessing birth records; Alek Buffa, who helped with data collection; and those women in each of the villages who completed the survey themselves, then encouraged and aided their peers to complete the survey as well. Thanks to Harold Neel for his continued local support, without which this study would not have been possible. 


\section{References}

Abu-Saad K, Fraser D. 2010. Maternal nutrition and birth outcomes. Epidemiol Rev. 32:5-25.

Barker DJ. 2004. The developmental origins of adult disease. J Am Coll Nutr. 23:588S-595S.

Benton D, Haller J, Fordy J. 1995. Vitamin supplementation for 1 year improves mood. Neuropsychobiol. 32(2):98-105.

Brittain K, Myer L, Koen N, Koopowitz S, Donald KA, Barnett W, Zar HJ, Stein DJ. 2015. Risk factors for antenatal depression and associations with infant birth outcomes: Results from a South African birth cohort study. Paediatric and Perinatal Epidemiology. 29(6):504-514.

Chan CW, Iata H, Yaviong J, Kalkoa M, Yamar S, Taleo G, Isozumi R, Fukui M, Aoyama F, Pomer A et al. 2017. Surveillance for malaria outbreak on malaria-eliminating islands in Tafea Province, Vanuatu after Tropical Cyclone Pam in 2015. Epidemiology and infection. 145(1):4145.

Dancause KN, Dehuff C, Soloway LE, Vilar M, Chan C, Wilson M, Tarivonda L, Regenvanu R, Kaneko A, Garruto RM and others. 2011a. Behavioral changes associated with economic development in the South Pacific: health transition in Vanuatu. American journal of human biology : the official journal of the Human Biology Council 23(3):366-376.

Dancause KN, Laplante D, Oremus C, Fraser S, Brunet A, King S. 2011b. Disaster-related prenatal maternal stress influences birth outcomes: Project Ice Storm Early Human Development. 87:813-820.

Dancause KN, Laplante DP, Fraser S, Brunet A, Ciampi A, Schmitz N, King S. 2012a. Prenatal exposure to a natural disaster increases risk for obesity in $5 \frac{1}{2}$ year old children. Pediatric Research. 71:126-131.

Dancause KN, Mutran D, Elgbeili G, Laplante DP, Kildea S, Stapleton H, McIntyre D, King S. 2017. Dietary change mediates relationships between stress during pregnancy and infant head circumference measures: the QF2011 study. Matern Child Nutr. 13(3).

Dancause KN, Veru F, Andersen RE, Laplante DP, King S. 2013a. Prenatal stress due to a natural disaster predicts insulin secretion in adolescence. Early human development. 89(9):773776.

Dancause KN, Vilar M, Chan C, DeHuff C, Wilson M, Soloway LE, Tarivonda L, Regenvanu R, Kaneko A, Garruto RM and others. 2012b. Patterns of childhood and adolescent overweight and obesity during health transition in Vanuatu. Public health nutrition 15(1):158-166.

Dancause KN, Vilar M, Wilson M, Soloway LE, DeHuff C, Chan C, Tarivonda L, Regenvanu R, Kaneko A, Lum JK and others. 2013b. Behavioral risk factors for obesity during health transition in Vanuatu, South Pacific. Obesity (Silver Spring) 21(1):E98-E104. 
Ellman LM, Schetter CD, Hobel CJ, Chicz-DeMet A, Glynn LM, Sandman CA. 2008. Timing of fetal exposure to stress hormones: Effects on newborn physical and neuromuscular maturation. Developmental Psychobiology. 50(3):232-241.

Eriksson H, Albert J, Albert S, Warrne R, Pakoa K, Andrew N. 2017. The role of fish and fisheries in recovering from natural hazards: Lessons learned from Vanuatu. Environ Sci Policy. 76:50-58.

Food and Agriculture Organization (FAO). 2010. Guidelines for measuring household and individual dietary diversity. Rome: Food and Agriculture Organization of the United Nations.

Frith AL, Naved RT, Persson LA, Frongillo EA. 2013. Early prenatal food supplementation ameliorates the negative association of maternal stress with birth size in a randomised trial. Matern Child Nutr. 11(4):537-549.

Glynn LM, Wadhwa PD, Dunkel-Schetter C, Chicz-Demet A, Sandman CA. 2001. When stress happens matters: effects of earthquake timing on stress responsivity in pregnancy. Am J Obstet Gynecol. 184(4):637-642.

Government of Vanuatu. 2015. Vanuatu: Post-Disaster Needs Assessment, Tropical Cyclone Pam, March 2015. Port Vila: Government of Vanuatu.

Government of Vanuatu. 2009. The Vanuatu mental health policy and plan, 2009-2015. Port Vila: Vanuatu Ministry of Health, Government of Vanuatu.

Haider BA, Bhutta ZA. 2015. Multiple-micronutrient supplementation for women during pregnancy. Cochrane Database Syst Rev.(11):CD004905.

Hobel CJ, Goldstein A, Barrett ES. 2008. Psychosocial stress and pregnancy outcome. Clin Obstet Gynecol. 51(2):333-348.

Imdad A, Bhutta ZA. 2012. Maternal Nutrition and Birth Outcomes: Effect of Balanced ProteinEnergy Supplementation. Paed Perinat Epidemiol. 26(Suppl. 1):178-190.

Kaplan BJ, Crawford SG, Field CJ, Simpson JS. 2007. Vitamins, minerals, and mood. Psych Bull. 133(5):747-760.

King S, Dancause K, Turcotte-Tremblay A-M, Veru F, Laplante DP. 2012. Using natural disasters to study the effects of prenatal maternal stress on child health and development. Birth Defects Research Part C: Embryo Today: Reviews. 96(4):273-288.

King S, Kildea S, Austin MP, Brunet A, Cobham VE, Dawson PA, Harris M, Hurrion EM, Laplante DP, McDermott BM, McIntyre HD, O’Hara MW, Schmitz N, Stapleton H, Tracy SK, Vaillancourt C, Dancause KN, Kruske S, Reilly N, Shoo L, Simcock G, TurcotteTremblay AM, Yong Ping E. 2015. QF2011: A protocol to study the effects of the Queensland Flood on pregnant women their pregnancies and their children's early development. BMC Pregnancy Childbirth. 15:109. 
King S, Laplante DP. 2015. Using natural disasters to study prenatal maternal stress in humans. Adv Neurobiol. 10:285-313.

Laplante DP, Barr RG, Brunet A, Galbaud du Fort G, Meaney MJ, Saucier JF, Zelazo PR, King S. 2004. Stress during pregnancy affects general intellectual and language functioning in human toddlers. Pediatr Res. 56(3):400-410.

Laplante DP, Brunet A, Schmitz N, Ciampi A, King S. 2008. Project Ice Storm: Prenatal maternal stress affects cognitive and linguistic functioning in 51/2-year-old children. J Am Acad Child Adolesc Psychiatry. 47(9):1063-1072.

Lazinski MJ, Shea AK, Steiner M. 2008. Effects of maternal prenatal stress on offspring development: a commentary Archives of Women's Mental Health. 11:363-375

Lederman SA, Rauh V, Weiss L, Stein JL, Hoepner LA, Becker M, Perera FP. 2004. The effects of the World Trade Center event on birth outcomes among term deliveries at three lower Manhattan hospitals. Environmental Health Perspectives. 112:1772-1778.

Lee AC, Booth A, Challen K, Gardois P, Goodacre S. 2014. Disaster management in low- and middle-income countries: scoping review of the evidence base. Emergency medicine journal : EMJ. 31(e1):e78-83.

Liu GT, Dancause K, Elgbeili G, Laplante DP, King S. 2016. Disaster-related prenatal maternal stress explains increasing amounts of variance in body composition through childhood and adolescence: Project Ice Storm. Environ Res. 150:1-7.

Loret de Mola C, Araújo de França GV, de Avila Quevedo L, Lessa Horta B. 2014. Low birth weight, preterm birth and small for gestational age association with adult depression: systematic review and meta-analysis. Brit J Pyschiatry. 205:340-347.

Maric NP, Dunjic B, Stojiljkovic DJ, Britvic D, Jasovic-Gasic M. 2010. Prenatal stress during the 1999 bombing associated with lower birth weight-a study of 3,815 births from Belgrade. Archives of women's mental health. 13(1):83-89.

Meghea CI, Rus IA, Chereches RM, Costin N, Caracostea G, Brinzaniuc A. 2014. Maternal smoking during pregnancy and birth outcomes in a sample of Romanian women. Cent Eur J Public Health. 22(3):153-158.

Monk C, Spicer J, Champagne FA. 2012. Linking prenatal maternal adversity to developmental outcomes in infants: the role of epigenetic pathways. Dev Psychopathol. 24(4):1361-1376.

Mulligan CJ, D'Errico NC, Stees J, Hughes DA. 2012. Methylation changes at NR3C1 in newborns associate with maternal prenatal stress exposure and newborn birth weight.

Epigenetics. 7(8):853-857. 
Nasiri Amiri F, Mohamadpour RA, Salmalian H, Ahmadi AM. 2010. The association between prenatal anxiety and spontaneous preterm birth and low birth weight. Iranian Red Crescent Medical Journal. 12(6):650-654.

Nasreen HE, Kabir ZN, Forsell Y, Edhborg M. 2010. Low birth weight in offspring of women with depressive and anxiety symptoms during pregnancy: Results from a population based study in Bangladesh. BMC Public Health. 10:515.

O'Donnell MH, Behie AM. 2013. Effects of bushfire stress on birth outcomes: A cohort study of the 2009 Victorian Black Saturday bushfires. International Journal of Disaster Risk Reduction. 5:98-106.

Olszowy KM, Pomer A, Dancause KN, Sun C, Silverman H, Lee G, Chan CW, et al. 2015. Impact of modernization on adult body composition on five islands of varying economic development in Vanuatu. American journal of human biology. 27(6):832-844.

Olszowy KM, Sun C, Silverman H, Pomer A, Dancause KN, Chan CW, Lee G, et al. 2017. Secular change in adult stature associated with modernization in Vanuatu. American journal of human biology. 29(5).

Ramchandani PG, Richter LM, Norris SA, Stein A. 2010. Maternal prenatal stress and later child behavioral problems in an urban South African setting. J Am Acad Child Adolesc Psychiatry. 49(3):239-247.

Rondó PHC, Ferreira RF, Nogueira F, Ribeiro MCN, Lobert H, Artes R. 2003. Maternal psychological stress and distress as predictors of low birth weight, prematurity and intrauterine growth retardation. European Journal of Clinical Nutrition. 57(2):266-272.

Rothberg AD, Shuenyane E, Lits B, Strebel PM. 1991. Effect of stress on birth weight in two Johannesburg populations. South African Medical Journal. 79(1):35-38.

Ruwanpathirana T, Fernando DN. 2014. Risk factors for 'Small for Gestational Age Babies'. Indian Journal of Pediatrics. 81(10):1000-1004.

Sanguanklin N, McFarlin BL, Park CG, Giurgescu C, Finnegan L, White-Traut R, Engstrom JL. 2014. Effects of the 2011 Flood in Thailand on birth outcomes and perceived social support. J Obstet Gynecol Neonatal Nurs. 43(4):435-44.

Shah PS, Ohlsson A, Knowledge Synthesis Group on Determinants of Low Birth Weight, Preterm Birth. 2009. Effects of prenatal multimicronutrient supplementation on pregnancy outcomes: a meta-analysis. CMAJ. 180(12):E99-108.

Sun C, Pomer A, Dancause KN, Chan CW, Olszowy KM, Silverman H, Lee G, et al. 2017. Ownership of consumer electronics is associated with measures of adiposity during health transition in Vanuatu. American journal of human biology. 29(2). 
Torche F, Kleinhaus K. 2012. Prenatal stress, gestational age and secondary sex ratio: the sexspecific effects of exposure to a natural disaster in early pregnancy. Human reproduction.

27(2):558-567.

Valladares E, Peña R, Ellsberg M, Persson LÅ, Högberg U. 2009. Neuroendocrine response to violence during pregnancy: Impact on duration of pregnancy and fetal growth. Acta Obstetricia et Gynecologica Scandinavica. 88(7):818-823.

Wado YD, Afework MF, Hindin MJ. 2014. Effects of maternal pregnancy intention, depressive symptoms and social support on risk of low birth weight: a prospective study from southwestern Ethiopia. PLoS ONE. 9(5):p e96304

Walhovd KB, Fjell AM, Brown TT, Kuperman JM, Chung Y, Hagler DJ, et al. 2012. Long-term influence of normal variation in neonatal characteristics on human brain development. Proc Natl Acad Sci U S A, 109(49), 20089-20094.

Weaver LJ, Hadley C. 2009. Moving beyond hunger and nutrition: a systematic review of the evidence linking food insecurity and mental health in developing countries. Ecol Food Nutr. 48(4):263-284.

Weiss DS, Marmar CR. 1997. The Impact of Event Scale - Revised. In: Wilson JP, Keane TM, editors. Assessing psychological trauma and PTSD: A practitioner's handbook. New York: Guilford Press, 399-411.

Weitz CA, Olszowy KM, Dancause KN, Sun C, Pomer A, Silverman H, Lee G, et al. 2017. Rolling tobacco in banana leaves, newspaper, or copybook paper associated with significant reduction in lung function in Vanuatu. Asia Pac J Public Health. 29(3):180-188.

World Food Program (WFP). 2015. Vanuatu: Tropical Cyclone Pam. Version 1, 17 March 2015. https://www.wfp.org/content/vanuatu-tropical-cyclone-pam.

World Health Organization (WHO). 2014. Global Nutrition Targets 2025: Low birth weight policy brief. Geneva: World Health Organization.

http://www.who.int/nutrition/publications/globaltargets2025_policybrief_lbw/en/

World Health Organization (WHO). 2017. The WHO child growth standards: weight-for-age. http://www.who.int/childgrowth/standards/en/.

Xiong X, Harville EW, Mattison DR, Elkind-Hirsch K, Pridjian G, Buekens P. 2008. Exposure to Hurricane Katrina, post-traumatic stress disorder and birth outcomes. The American journal of the medical sciences. 336(2):111-115.

Xiong X, Harville EW, Mattison DR, Elkind-Hirsch K, Pridjian G, Buekens P. 2010. Hurricane Katrina experience and the risk of post-traumatic stress disorder and depression among pregnant women. American Journal of Disaster Medicine. 5(3):181-187. 
Zhu P, Tao F, Hao J, Sun Y, Jiang X. 2010. Prenatal life events stress: implications for preterm birth and infant birthweight. American Journal of Obstetrics and Gynecology. 203(1):34.e3134.e38. 
Appendix 1: Questionnaire items from the Impact of Events Scale - Revised (Weiss and Marmar 1997) used in the current study

\section{Intrusive thoughts}

I had dreams about it

I had trouble staying asleep

I had waves of strong feelings about it

Hyperarousal

I was jumpy and easily startled

Reminders of it caused me to have physical reactions, such as sweating, trouble breathing, nausea, or a pounding heart

I felt watchful and on-guard

Avoidance

I felt as if it hadn't happened or wasn't real

I tried not to talk about it

I tried not to think about it 
Appendix 2: Correlations between key predictor and outcome variables

\begin{tabular}{|c|c|c|c|c|c|c|c|c|c|c|c|c|}
\hline & & 1 & 2 & 3 & 4 & 5 & 6 & 7 & 8 & 9 & 10 & 11 \\
\hline \multirow[t]{2}{*}{ 1. Age } & $\mathrm{r}$ & --- & & & & & & & & & & \\
\hline & p-value & & & & & & & & & & & \\
\hline \multirow[t]{2}{*}{ 2. Parity } & $\mathrm{r}$ & 0.711 & --- & & & & & & & & & \\
\hline & p-value & $<0.001$ & & & & & & & & & & \\
\hline \multirow{2}{*}{$\begin{array}{l}\text { 3. Education } \\
\text { (years) }\end{array}$} & $\mathrm{r}$ & -0.167 & -0.247 & --- & & & & & & & & \\
\hline & $\mathrm{p}$-value & 0.167 & 0.039 & & & & & & & & & \\
\hline \multirow[t]{2}{*}{ 4. Exposure days } & $\mathrm{r}$ & 0.085 & 0.030 & 0.065 & --- & & & & & & & \\
\hline & $\mathrm{p}$-value & 0.484 & 0.805 & 0.595 & & & & & & & & \\
\hline \multirow{2}{*}{$\begin{array}{l}\text { 5. Objective } \\
\text { hardship }\end{array}$} & $\mathrm{r}$ & 0.124 & 0.245 & -0.424 & -0.033 & --- & & & & & & \\
\hline & p-value & 0.306 & 0.041 & 0.000 & 0.787 & & & & & & & \\
\hline \multirow{2}{*}{$\begin{array}{l}\text { 6. Dietary } \\
\text { diversity }\end{array}$} & $\mathrm{r}$ & -0.232 & -0.158 & 0.156 & -0.111 & -0.166 & --- & & & & & \\
\hline & $\mathrm{p}$-value & 0.054 & 0.193 & 0.199 & 0.359 & 0.169 & & & & & & \\
\hline \multirow{2}{*}{$\begin{array}{l}\text { 7. Days without } \\
\text { food }\end{array}$} & $\mathrm{r}$ & -0.020 & 0.001 & -0.095 & 0.077 & 0.025 & -0.238 & --- & & & & \\
\hline & p-value & 0.874 & 0.995 & 0.447 & 0.538 & 0.842 & 0.054 & & & & & \\
\hline \multirow{2}{*}{$\begin{array}{l}\text { 8. Days without } \\
\text { water }\end{array}$} & $\mathrm{r}$ & 0.076 & 0.163 & -0.154 & -0.071 & 0.222 & -0.166 & 0.409 & --- & & & \\
\hline & $\mathrm{p}$-value & 0.547 & 0.194 & 0.222 & 0.575 & 0.075 & 0.186 & 0.001 & & & & \\
\hline \multirow[t]{2}{*}{ 9. Distress } & $\mathrm{r}$ & 0.211 & 0.153 & -0.336 & -0.112 & 0.284 & -0.374 & 0.141 & 0.092 & --- & & \\
\hline & $\mathrm{p}$-value & 0.084 & 0.214 & 0.005 & 0.364 & 0.019 & 0.002 & 0.265 & 0.474 & & & \\
\hline \multirow{2}{*}{$\begin{array}{l}\text { 10. Birthweight } \\
\text { (g) }\end{array}$} & $\mathrm{r}$ & 0.024 & 0.128 & -0.205 & 0.075 & 0.041 & -0.055 & 0.138 & 0.277 & -0.214 & --- & \\
\hline & $\mathrm{p}$-value & 0.842 & 0.292 & 0.089 & 0.536 & 0.739 & 0.653 & 0.268 & 0.026 & 0.080 & & \\
\hline \multirow{2}{*}{$\begin{array}{l}\text { 11. Birthweight } \\
\text { Z-score }\end{array}$} & $\mathrm{r}$ & -0.014 & 0.102 & -0.203 & 0.115 & 0.016 & -0.044 & 0.174 & 0.250 & -0.238 & 0.986 & --- \\
\hline & $\mathrm{p}$-value & 0.907 & 0.402 & 0.092 & 0.342 & 0.894 & 0.716 & 0.162 & 0.044 & 0.051 & $<0.001$ & \\
\hline
\end{tabular}


Table 1: Characteristics of women in the current analyses $(n=70)$

\begin{tabular}{lr}
\hline Variable & Mean (SD) \\
\hline Parity & $1.9(1.7)$ \\
Maternal age & $25.8(4.9)$ \\
Maternal education (years) & $7.9(4.2)$ \\
Timing of exposure & $126(74)$ \\
Objective hardship & $10.7(1.7)$ \\
Dietary diversity & $3.1(1.2)$ \\
Days without adequate food & $14.2(21.6)$ \\
Days without adequate water & $11.0(19.6)$ \\
Distress & $2.2(0.9)$ \\
\hline
\end{tabular}


Table 2: Summary of regression models (standardized coefficients $\beta$, and p-values) testing individual predictors of birthweight

\begin{tabular}{lrrrrrr}
\hline Variable & \multicolumn{2}{c}{$\begin{array}{c}\text { Objective } \\
\text { Hardship (1) }\end{array}$} & Dietary Diversity (2) & \multicolumn{2}{c}{ Distress (3) } \\
& $\beta$ & p-value & $\beta$ & p-value & $\beta$ & p-value \\
Parity & 0.046 & 0.294 & 0.163 & 0.346 & 0.137 & 0.404 \\
Maternal age & -0.016 & 0.258 & -0.183 & 0.292 & -0.112 & 0.495 \\
Maternal education (years) & -0.021 & 0.104 & -0.184 & 0.142 & -0.283 & 0.024 \\
Sex of baby & -0.196 & 0.048 & -0.243 & 0.053 & -0.249 & 0.036 \\
Timing of exposure & 0.001 & 0.301 & 0.126 & 0.142 & 0.105 & 0.360 \\
$\begin{array}{l}\text { Cyclone exposure variable } \\
(1,2 \text {, or 3) }\end{array}$ & -0.022 & 0.489 & 0.010 & 0.937 & -0.317 & 0.012 \\
& & & & & & \\
\hline
\end{tabular}


Table 3: Multivariate regression models testing all cyclone-related variables together

\begin{tabular}{lcc}
\hline Variable & $\beta$ & p-value \\
\hline Parity & 0.149 & 0.377 \\
Maternal age & -0.132 & 0.434 \\
Maternal education (years) & -0.294 & 0.028 \\
Sex of baby & -0.239 & 0.048 \\
Timing of exposure & 0.092 & 0.435 \\
Objective hardship & -0.042 & 0.744 \\
Dietary diversity & -0.102 & 0.420 \\
Distress & -0.344 & 0.011 \\
\hline
\end{tabular}

